\title{
Picturing Distance: Ed Ruscha's Los Angeles Photobooks.
}

It's not simply a story about a type of architecture that I might be interested in. It also echoes a memory I had of watching movies when I was young. It seemed like all movies would have a train in them. Invariably, they had the camera down on the tracks and shot this train so it appeared as though it was coming from nowhere, from a little point in the distance, to suddenly zooming in a filling your total range of vision. ${ }^{1}$

The notion of "topography" works in two or three dimensions. It can refer to the arrangement of physical features on the landscape, or to its representation on the surface of a map. Ed Ruscha's photobooks preserve this play between two and three dimensions, drawing attention to both the graphic qualities of the photograph as a flat entity and the photobook as a three-dimensional object. William Jenkins' use of the term to title George Eastman House's 1975 exhibition "New Topographics: Photographs of a Manaltered Landscape" was intended, he argues in the catalogue essay, to suggest a disengaged attitude to content directly inspired by Ruscha's work. ${ }^{2}$ In is connection to mapping and surveying, a topographical attitude is one of measurement, or of notation, rather than of narrative or appraisal. He sees in Ruscha's books "qualities of rigorous purity, deadpan humor and a casual disregard for the importance of the images," photographs "stripped of any artistic frills and reduced to an essentially topographic state, conveying substantial amounts of visual information but eschewing entirely the aspects of beauty, emotion and opinion". 3 The connection Jenkins made between this work and photobooks by Ruscha such as Twentysix Gasoline Stations (1962), Some Los Angeles Apartments (1965), Every Building on the Sunset Strip (1966), ThirtyFour Parking Lots in Los Angeles (1967), Nine Swimming Pools (1968) and Some Los Angeles Apartments (1965) was about photographic style; both Ruscha's work and the work of the photographers in this exhibition mobilized a type of look where "the appearance of neutrality was strictly maintained." This play with the look of neutrality (along with the deadpan humour that comes along with weakening affect and multiplying images), was indeed part of Ruscha's influence on photographers such as Lewis Baltz and Stephen Shore, as well as on Jenkins. ${ }^{5}$ The idea of "neutrality," however, only begins to indicate the complex ways in which Ruscha's photobooks work as publications, as photographs, and as objects to think with. In the pages that follow I will argue for a common thread that goes beyond neutrality, demonstrating how all three of these elements in Ruscha's photobooks a resistance to obvious affect, flat plane abstraction, and a consistent engagement with photographic and readerly point of view - come together to form an extended conceptual and visual meditation on "distance."

Susanna Newbury draws a line between Ruscha's vision of LA and the changes to architectural thinking of the sixties and early seventies manifest in works on the new West by Denise Scott Brown, 
Robert Venturi, Stephen Izenour and Reyner Banham. She points out that more or less all of the buildings in Thirtyfour Parking Lots were part of a post-war industrial boom in the Laurel Canyon and Wiltshire boulevard area. ${ }^{6}$ Ruscha photographs malls, theme parks and corporations like Lockheed and Rocketdyne as well as the Eileen Feather Figure Salon, and the Hollywood Bowl (fig 1).

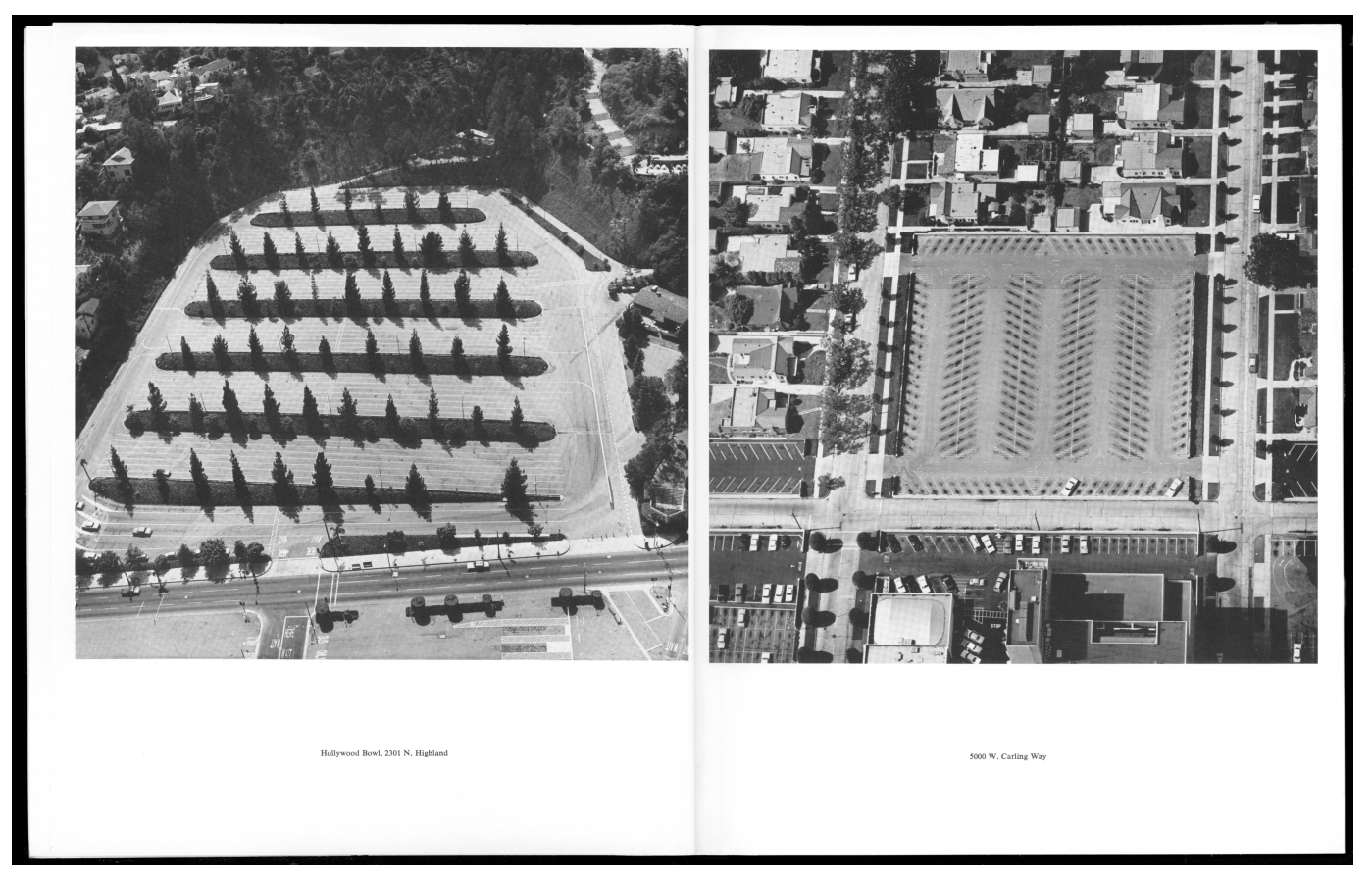

Newbury demonstrates that these large lots are those of the new giants that are wiping out any kind of small industry in the area, and that Twentysix Gasoline Stations similarly shows Mobil, Texaco et al edging out the mom-and-pop stations. Historically, this is true, however, because these photos are anti-didactic and anti-judgemental, there is no easy way to settle whether Ruscha's record of the infrastructure is meant as a critique or as a more neutral catalogue of the post-war West coast building boom. Any emotional and intellectual resonance in Ruscha's own photos is a good deal more ambivalent than a straightforward critique would be. ${ }^{7}$ Ruscha's emptying out of parking lots and real estate lots gives us a world that is much more orderly than, for example, Nicholas Nixon's shots of parking lots where the cars are present, and we can see human disorder and bad parking in evidence over the whole surface. (By contrast, Lewis Baltz's photographic presentation of California in New Topographics, and in The New Industrial Parks near Irvine, California (1974) is even more abstracted than Ruscha's.). Eleanor Antin compares Ruscha's parking lots to Alain Resnais' "neoclassical fantasy," Last Year at Marienbad, where, she says, Resnais also emptied out and reworked the environment. She calls Thirtyfour Parking Lots, "an elegant series of eighteenth-century concrete and asphalt gardens," remarking that: 
The empty parking lots unfold before and behind their buildings with geometric precision ...Positioning the camera eye up there in the sky displaces the event. Ruscha knows very well that down here on earth those asphalt parking lots are never empty. ${ }^{8}$

Indeed, although Ruscha's photography consistently engages with what it means to be in, move through, and look out at America, his photobooks almost refuse notions of inhabitation. Andy Warhol is said to have noted, looking at Twentysix Gasoline Stations, "Oh, I love it because there are no people in there," and Ruscha speaks of seeing a quietude in the empty swimming pools and blank pages of Nine Swimming Pools. ${ }^{9}$ Humans are here in their infrastructural traces, but Some Los Angeles Apartments only carries the most basic signs of individual people and the bays of Thirtyfour Parking Lots contain few parked cars. The erasure of the individual as photographic content is manifest in the scale of these photobooks too - the books themselves are small, and the cityscapes even smaller — as well as in the absence of any human proxies or subjects in the photographs.

This sense of a formalized, emptied environment has its analogue in the way Ruscha's photobooks play down various elements of artistic intentionality. In these books, the author/artist is constructed as distanced too. In order to create these sequences of images, Ruscha followed what Margaret Iversen argues is the equivalent of an "event score," presenting photographs as a performative fulfilment of a premise rather than as the capture of a privileged instant. Because Ruscha decided on the titles first and then obtained the photographs, they can, she argues, "readily be understood as a contracted form of an instruction: 'record 26 gasoline stations along Route 66'." "Given that Ruscha shot many of the photographs in Real Estate Opportunities, Nine Swimming Pools, and Some Los Angeles Apartments himself, the delegation of work in Thirtyfour Parking Lots is not perhaps as important in this regard as his more consistent evocation of military, real estate and home photographers. There is an assertion of stylelessness in the lack of cropping of these photos which moves any centre of interest away from the golden section, and from other strong positions on the pictorial planes. The unassuming size of the books contributes to this sense of unassertiveness. The avoidance of lyricism in the photographs' narrow tonal range and the lack of darkroom manipulation parallels the avoidance of pathos in the lack of visual traces or presences of individual people. Bluntly informative captions emphasize the deliberately mundane nature of Ruscha's subjects.

This step away from the photograph as record of an assertive, decisive, agency, and from its status as a spontaneous capture of the unique instant, is very much part of an anti-subjective impulse that runs through late sixties and early seventies art. ${ }^{11}$ Jenkins quotes Lewis Baltz's statement that "the ideal photographic document would appear to be without author or art," but this is also the era of Roland Barthes' "Death of the Author," of the anonymized arts of Daniel Buren and BMPT, of the Art and Language group, and of Fluxus. ${ }^{12}$ As Britt Salvesen points out in her essay on the New Topographic 
photographers, an aesthetic of objectivity encompasses many of the artistic and intellectual currents running through photographic based-work of this period:

ultimately, objectivity proved so useful as a stylistic linchpin because it could be correlated with a variety of authorial stances: non-engagement (Walker Evans) egalitarianism (cultural landscape studies), eclecticism (Learning From Las Vegas), irony (Ed Ruscha), anti-romanticism (Robert Smithson), activism (environmentalism), and anonymity (nineteenth-century survey photography and other utilitarian documents). ${ }^{13}$

Conceptualism, too, sought a version of the artist who, as Sol LeWitt put it in the explanatory notes for Serial Project \#1, "functions merely as a clerk cataloging the results of his premise."14 There is a reaction against Abstract Expressionism in Ruscha's methods; he trained at Chouinard (now Cal Arts) at the height of Abstract Expressionism's popularity, and he talks of it being "an enormous freedom to be premeditated" about his works, to imagine then work through the stages to execute something. ${ }^{15}$ However, neither this premeditation, nor his love of Marcel Duchamp's work (discussed below), leads him into the dematerialization of pure Conceptualism. Ruscha maintains that Conceptualism always denied its use of the visual ("they all have visual statements"), and that, against this, he remains a resolutely visual artist. ${ }^{16}$ Like Warhol, Roy Lichtenstein and James Rosenquist, Ruscha worked commercially before and alongside his early work, and the conditions for authorship for blue-collar workers may have also informed the interrogation of the notion of the role of the expressive artist in this period. For Thirtyfour Parking Lots this authorial distance extends to a measure of "deskilling" too: the photos were taken by Art Alanis, a commercial photographer. The traffic between graphic arts and fine arts in this period is explored by Thomas E. Crow in The Long March of Pop, and it is significant to note that Ruscha's training at Chouinard Institute was also in graphic design and print layout. Ruscha's play with typography and with signs and hoarding in photographs such as Conoco, Alburquerque, New Mexico (1962) works to disengage text-based images from the utilitarian considerations of graphic design. (Fig 2.) 


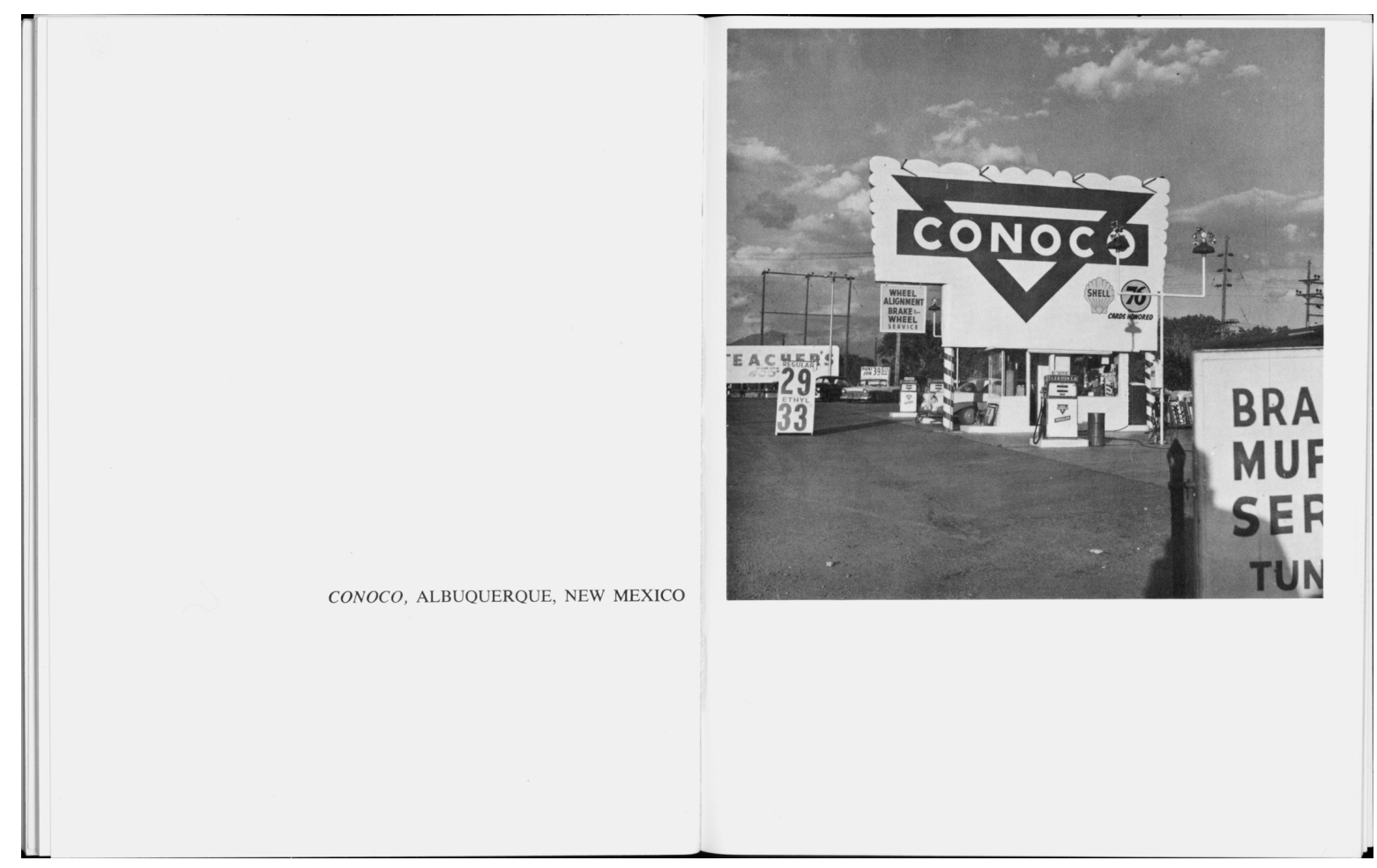

Despite the movement away from expression and intentionality in these photobooks, Ruscha is very much present in the mythos of these works as their creator. He appears in photos touching and holding the books, and advertisements for Ruscha's work in the Ferus gallery construct Ruscha's persona as young, hip, witty and virile. ${ }^{17}$ This marking of the work as Ruscha's is thus in a productive tension with other measures that seek to elide the figure or message of the photographer-artist. Ruscha states that he had a notion to photograph things "dead head straight on without much emotion," because "lack of emotion is almost like...a little like no style, in a way," he explains, ${ }^{18}$ but clearly consistent refusal of the main markers of pictorialist landscape can indeed become a distinct style. ${ }^{19}$ Indeed, Ruscha's style is recognisable enough to have precipitated a number of parodies and homages. ${ }^{20}$ (In describing the aesthetic of distance in the New Topographic photographers, Salvesen points us towards Susan Sontag's "On Style," a piece that is contemporaneous with Ruscha's work, which asserts that it is precisely these varying distances from subject matter which are what we might call "style" in a wider sense. $\left.{ }^{21}\right)$ Ruscha's version of photography as "a little like no style" thus works, paradoxically, to reaffirm his style. ${ }^{22}$ Both physical and emotional distance are at stake in these photos, then. The sense of physical distance that is captured in the point of view of, for example, Twentysix Gas Stations, with their consistently low level, shot-from-the-hip across the road perspective, asks us to use the photographer as proxy to place ourselves physically in the act of viewing, whilst the construction of an implied dispassionate artist - particularly in evidence here in the blurred photo labelled as "Whiting Bros., Near Ludlow, California" -- asks us, too, to remove ourselves affectively. 
A much-quoted remark of Ruscha's from 1965 finds him side-lining the aesthetic qualities of the medium: "photography is dead as a fine art; its only place is in the commercial world, for technical or information purposes," he states. ${ }^{23}$ Although Ruscha's opinion seems to change over the years (in 1999 the parking lot photographs were printed as new, 15 inch square, silver gelatin prints) this emphasis on technical data is useful as a sense of the tenor of the photobooks, if not their institutional context. Indeed, one of the venues for the publication of Ruscha's work was Dan Graham's edition of the multimedia magazine in a box, Aspen, which concentrated on "Art and Information," and placed Ruscha's Thirtyfour Parking Lots in the same box as photographic and text-based elements of environmental work by Smithson and Oppenheim, as experimental music scores by Steve Reich and Philip Glass which derived from processual operations, and conceptual work by Yvonne Rainer, Richard Serra, Terry Atkinson and Michael Baldwin, and Eleanor and David Antin. ${ }^{24}$ Both environmental work, such as Smithson's and Oppenheim's, and conceptual work such as Graham's and LeWitt's was dependent on photographic and textual representation for its circulation and explanation. Both material, and dematerialized art, then, came together in this period in their dependence on "information" to circulate, and, as Charles Gagnon states in "Handling Conceptual Art," "in many cases materials and techniques were chosen because they were deemed to be neutral, unexpressive" or "did not belong to the usual techniques of art making." 25 Working as "Eddie Russia" - the layout artist for Artforum from 1965 to 1969 - Ruscha would have known contemporary made-for-magazine pieces, as well as the secondary documentary presentations of large sculptural works, well. ${ }^{26}$ In this milieu "information" is the answer to the question of how to record an art experience that is both overwhelmingly physical, and which has a logical, in some cases overtly mathematical or scientific, intellectual form. This notion of 'information' is another modality of what I am calling "distance". It creates a forum for modes of apprehending the arts ostensibly outside of emotional empathy, or aesthetic appreciation.

Information for Ruscha has a more humorous tone than it has for Graham, or for Smithson; for Ruscha information seems to have an alluring absurdity. (So, for example, the photograph of a Conoco gasoline station reproduced above is cropped to produce text - bra, and a "muf" - that leads the viewer to speculate both on a female sexual symbolism in the triangle shape above them, and on the improbability of these references.) Noticing something that might remain unnoticed is a mischievous gesture that comically over-inflates the insignificant. In an interview with A.D. Coleman in 1972, Ruscha invents a being called the "Information Man" whose grasp on dry data is total:

The Information Man is someone who comes up to you and begins telling you stories and related facts about a particular subject in your life. He came up to me and said, 'Of all the books of yours that are out in the public, only 171 are placed face up with nothing covering them; 2026 are in vertical positions in libraries, and 2715 are under books in stacks. The most weight on a single book is sixty-eight pounds, and that is in the city of 
Cologne, Germany, in a bookstore. Fifty-eight have been lost; fourteen have been totally destroyed by water or fire' ... Now wouldn't it be nice to know these things? ${ }^{27}$

The information man notices, but does not obviously judge, leaving the situation and choice of focus to carry bathos. In many of the more empty photographs, noticing can be taken as a form of affirmation, if not direct judgement, but it is a form of attention that is witty in its shift of focus onto the overlooked, and ambivalent in that it offers no purport for this shift of attention. The sense of the artist as a centre for meaning is still present, but the kinds of meaning he summons are more or less topographical they are about place, position, mass, material condition. They are also broadly inconsequential; it would be nice to know these things, but niceness is the opposite of necessity or utility. Eleanor Antin's deadpan commentary is a good match for Ruscha's in this regard. Antin makes clear how the serialism in and of his books is producing a sense of meaningfulness whilst, through a series of exaggerated and inconsequential explications, she parodies the excesses and inaccuracies that seem to ensue if one follows up this sense of meaningfulness with an earnest search for the information in these photos. "Anyone who takes twenty-six photographs of the same subject and packages it as a complete work might be expected to have a point of view about the material," she suggests, but "we already possess more information about gas stations than Ruscha gives us." ${ }^{28}$ (Robert Adams' comment that "anybody who simplifies the confusion of life into a composition is making personal judgements from the start" is also germane. ${ }^{29}$ ) Taken in this way Ruscha's works are a satire of the notion of obviousness itself; the snapshot aesthetic is a marker of a self-evidence that is not all it seems to be. This play between salient and non-salient detail might also be seen in the ambiguity created by the printing of the photobooks in halftones. As halftones the images lose much of the fineness of grain which would lead the viewer into inspecting specific elements of the view, but nevertheless, they do still capture incidental details, albeit ones which cannot be rationalized into any narrative or "message."

One obvious precedent for this proto-conceptual play with information and significance in Ruscha's photography is in Marcel Duchamp's work. One marker of Duchamp's influence in the midsixties might be found Arturo Schwarz's creation of eight authorized sets of replicas of the readymades between 1964 and 1965 (the same time as Ruscha would have been working on Some Los Angeles Apartments); here Duchamp worked with Schwarz to produce his own work in serial. ${ }^{30}$ Ruscha's version of the readymade presents what might be seen as deliberately tedious material that is framed as unwilled, if not actually "found." Indeed, Ruscha comments that "I feel that the spirit of his [Duchamp's] work is stronger in my books than in anything else," and calls his photobooks "an extension of a readymade in photographic form." ${ }^{\prime 1}$ Ruscha speaks of what it means to respond to Duchamp's work as a kind of "mystery": "the ultimate mystery of his work is its value. It's hard to be taught how to look at Duchamp's work, it has to be felt somehow." ${ }^{32}$ He speaks specifically of Duchamp's Coffee Grinder as "like a mystery that did not need explaining to me. ... it has a dedication to certain classic truths about the 
making of a picture and the illustrating of an object and then it also has this inane-ness to it" ${ }^{33}$ This offhand talk of mystery is the marker of a resistance to interpretation but might also constitute a name for the affective charge an everyday object has when it is re-seen as an art object. In other words, the kind of mystery in Duchamp's inanity might be seen as a source of the irony, or bathos, in Ruscha's photobooks, too. This sense that an object is both what it is - inane perhaps - and something else too, produces a doubleness that might be taken as the equivalent of the doubleness of literary irony, where the narration and the narrated present discordant messages. In this, it is part of a cluster of feelings about the photobooks that mark moments of internal tension: "paradox and absurdity have just always been really delicious to me. The intangible gets to me, the subjective gets to me, the emotional and intuitive gets to me," Ruscha has stated. ${ }^{34}$

The photo as information, or as a product of LeWitt's conceptual idea as "machine that makes the art," does not therefore mean that it is affectively blank. "It is the objective of the artist who is concerned with conceptual art to make his work mentally interesting to the spectator, and therefore usually he would want it to be emotionally dry," LeWitt states, but even dryness, I would argue, is an affect. ${ }^{35}$ Ruscha's presentation of mystery is a quiet one, and the sense of something extra, a resonance that happens in the photobooks' distanced form and subject, might be taken as the kind of "weak affect" Sianne Ngai writes of in her essay on the "Merely Interesting." Here, using Ruscha's photobooks as one of her examples, Ngai looks to describe the subtle blend of triviality with a snagging of our attention that is marked by calling something "merely interesting" — as characterized by a "wavering between the boring and interesting" - a "feeling so low in intensity that it can even be hard to say whether it counts as satisfaction or dissatisfaction, feels good or bad to feel." 36 Ngai describes Ruscha's photobooks as "clearly engineered to keep affect on a low burner, generating, at most, tiny flares of interest like the 'small fires' appearing at regular intervals in Various Small Fires and Milk." ${ }^{37}$

The sheer emptiness of Ruscha's photos is brought to the forefront of our consciousness as viewers because of the work's presentation in serial. One deserted photograph is incidental; thirty-four or twenty-six empty landscapes constitute an aesthetic. The replication of any image alters its affect considerably. Repeated, an image seems muted as it is emptied out of its individuality, but this muting is replaced by a different form of weight and emotional resonance which is more to do with a feeling of teeming, or, in the case of many of Warhol's multiples, of inundation. Ruscha's compositional reliance on geometric shapes and oblique planes are emphasized as they are repeated, and aspects of the landscape such as trees or oil spills become motifs. As the photographer Frank Gohlke points out, the serial format nudges us to look for difference and sameness, working both to throw us back on the smallest details of the images as well as to seek the broadest possible correspondences: "The series is what gives the individual photograph its interest, although parking lots for example are interesting in themselves because there is variation. Tiny details within them become very interesting." ${ }^{38}$ (Fig 3). 


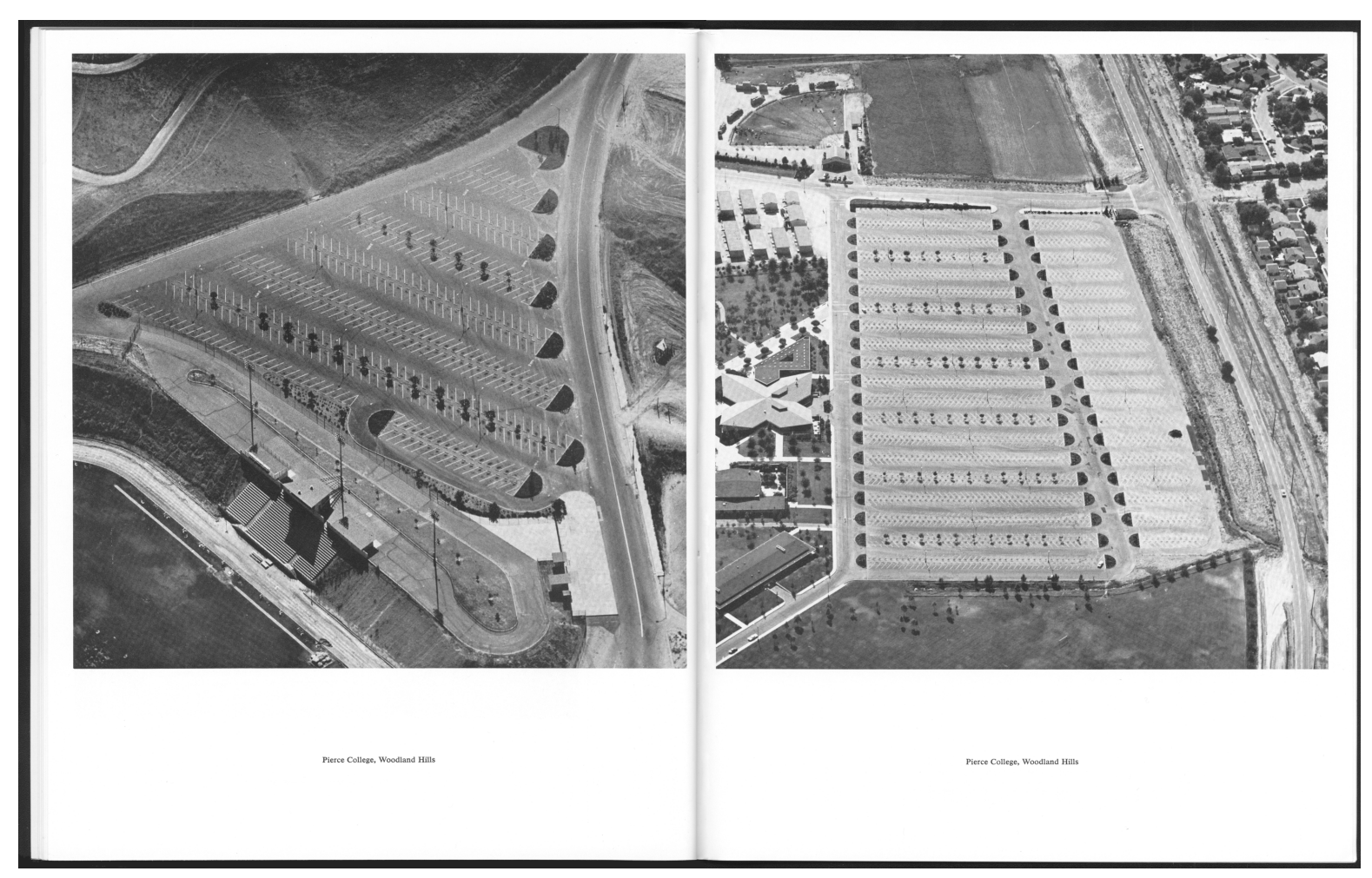

This presentation is heightened by binding the photos into a book where parallels and disjunctions are created by virtue of the photographs' position on the rectos and versos. The apartments move up and down in scale and in and out of the guttering; the cropping of the parking lots vary according to the shape of the lot, whilst the swimming pools and vacant lots remain constant. The gas stations, parking lots and swimming pools are punctuated by irregularly spaced blank or caption pages inserted, in part, to keep the spine of the book a satisfying thickness. Turning the page gives us a similar image in a similar position even more obviously than moving through the walls of a gallery would, and Ruscha's blank pages act self-reflexively, to keep us attentive to what we see and expect to see.

Salvesen convincingly argues that Ruscha's books aren't “as uniform as that artist would have us believe - instead the uniformity is largely an effect of seriality, which thus emerges as Ruscha's true innovation." ${ }^{39}$ Ruscha's seriality is slightly different to the mathematical formalism in mid-sixties conceptual pieces, or even the more obviously visual uniformity in Bernd and Hilla Becher's typological work. ${ }^{40}$ Instead there is a humour in the bringing together of things that are not usually counted, whose position in the background of our lives does not normally merit the privilege of cataloguing — vacant lots, car parks, empty streets, even vacant pages. Ruscha's photobooks attempt to mark sites without them becoming highly "marked" in terms of our attention. These books might be thought of as working to bring the perceptual background into the foreground but without the implication of an artist's expression, and with only minimal affect. The serialism of the works is part of the control of affect; looked at in isolation these photographs become absorbing. The eye finds texture, shadow and reflection, we start reading signs and labels, and we start reading the lines and marks of the parking lots' 
concrete. Read in serial though, our attention is moved from the markers of place, matter and process towards the repeated constructions of these images. The planes, perspective lines and elevations of the apartment blocks, patios, gasoline stations and car parks begin to function as the basic elements of composition. $^{41}$

Instead his use of lines, planes and surfaces are turning a topographic survey of the land into a question of what topos might mean for a photograph. The horizontality of the landscape seems to be producing elements of Ruscha's wider style, including his preference for a landscape canvas format, for the wide-screen panorama, for the horizontality of reading words and phrases in English as well as for the backgrounds of those later works. "Fundamentally, I'm an abstract artist. I respond to primal, basic aspects of art. The horizontal line. The vertical line. The works here are a series of manipulations using vertical and horizontals. I want to see things stretched," Ruscha states. ${ }^{42}$ In these more visually textured photographic works the detailed sense of place in the landscape features of Los Angles and Southern California -- features which are absent or elided in Ruscha's painting -- are in tension with the presentation of that land as geometrical, abstracted form. This strategy carries over to the photographs too in the case of the apartment blocks where, as Ken Allan points out, we are led to seek out the names and to contrast the romanticism of the Lee Tiki, Fountain Blu, Il Pompeii, and Capri with the brutality of the concrete structures. The way that the photographs emphasize this severity through accentuating the compositional lines of the buildings contributes to the effect captured by speaking of Ruscha's "irony": the patterning of tension between repetitive abstraction and idiosyncratic sense of place gives these pictures an additional sense of doubleness.

This end product is not however, primarily a Warholesque parody of consumerism and mechanical reproduction; these photos are too affectively distanced for that kind of commentary. Instead, this end product brings Ruscha into three dimensions, giving him a medium through which to take part in the kinds of contemporary investigations into objecthood we more usually associate with minimalist art. The phenomenological turn marked by minimalist sculpture was part of an impulse to challenge the idea of the expressive artist asserting his (usually his) unique vision through pliant material by bringing the agency of matter and of the environment of viewing back into consideration. The replacement of a romantic expression with a process or a system united Minimalist artists and Conceptual ones, and, in its anti-subjectivity, brings affective and physical distance together as prime concerns of the period. ${ }^{43}$ This extends to the patina of the books, too. There are a number of comments Ruscha has made that suggest that part of what his was aiming for in many of his works was a kind of look - a variety of surface and objecthood - that would be informed perhaps both by his place in the Los Angeles art world of the "finish fetishists" and by his training as a graphic designer. Ruscha speaks of the Los Angeles sense of "manufactured" finish being less of an influence on his painting (he remained an easel painter) then on his books. ${ }^{44}$ "What I really want is a professional polish, a clear-cut 
machine finish. This book is printed by the best printer west of New York. Look how well made and crisp it is. ... It is almost worth the money to have the thrill of 400 exactly identical books stacked in front of you," "I want the end product; that's what I'm really interested in"; "the book is the look, not the photograph." $" 45$

As Allan argues, throughout his career Ruscha has been engaged by the notion of "flatness" as both a magazine layout artist, but also in his later trompe l'oeil techniques. ${ }^{46}$ This investigation into the planar segues into one of volume, and then into recession. Indeed, as Allan points out, the first painting that Ruscha sold, Box Smashed Flat (Vicksburg) (1960-61), was a nominally two-dimensional representation of something that used to be three. In keeping with this attention to the objecthood of these overlooked items, Ruscha's 'flat' works — canvasses, drawings and books — are actually treated as three-dimensional, so the books are almost all the same size, bulked out with blank pages to make the spines the correct kind of thickness. Canvases such as Smash (1963) are treated as objects as well as planes when Ruscha places their titles along the canvas edge, and then draws them, rotating them through three dimensions (Smash Triptych, 1964). "I consider my books to be strictly visual materials. I even perceived them as bits of sculpture, in a way," Ruscha states. "They were three-dimensional, they were thick," "my painting were book covers in a way," he continues. ${ }^{47}$

So, as the paintings become books, the books become sculptural objects: drawings of these books include Hands Flipping Pages (Twentysix Gasoline Stations) 1963, Hand Showing Book Spine (Twentysix Gasoline Stations) 1963, and Hand Showing Book Cover (Twentysix Gasoline Stations) 1963. ${ }^{48}$ Photo, Riot, 400 Books (1963) also steps the viewer through these spatial permutations, ending with a drawing of a stack of books projecting through three-dimensions as if it were the Twentieth Century Fox logo, complete with searchlights. The sheer materiality of the books are emphasized in photographs such as those in Jerry McMillan's 1970 series which include Ed Ruscha with six of his books balanced on his head, Ed Ruscha covered with twelve of his books, and Ed Ruscha unfolding Every Building on the Sunset Strip. ${ }^{49}$ Here the kinds of concerns with positionality that I am calling "distance" is also functioning to highlight proximity. Remediation plays down their representative function, and gives the photobooks to us as body-sized objects, associating them with Ruscha's body in particular. ${ }^{50}$ This interest in what happens when three dimensions are printed and laid out in two, and then returned again to three is also evident in the layout of the books. Allan demonstrates the way images are juxtaposed in Some Los Angeles Apartments to use the gutters of the book to force an exaggerated perspective into some of the pictures so that they appear to rise from the book's spine, and pays close attention to Ruscha's drawing of 1965, Barrington Avenue, which has an apartment block turning into a blank curved page - a drawing of a photograph turning into a drawing again. ${ }^{51}$ In effect, here the book itself, and the page too, become topographies. This extends to Thirtyfour Parking Lots too; there 
is a visual pun between the high angle perspective of the reader with the book open in her or his hands and the overhead perspective of the aerial shot. ${ }^{52}$

Ruscha's emphasis on the compositional blocks of the apartments, swimming pools, gas stations and lots are thus produced by the photographic flattening of the depth of the landscape onto a planar surface. ${ }^{53}$ This becomes a compositional device, a way to divide up the pictorial field. "A photograph showed me how a subject would look flat. So I didn't have to make all those adjustments from nature. Other artists translate the three dimension of the real world into a two-dimensional image. The photograph did that for me," he explains. ${ }^{54}$ Rowell's purpose in "Ed Ruscha: Photographer" is to demonstrate how Ruscha's painting style drew from his photographic one, teaching him how to compose on the flat, but also inspiring "horizontal or diagonal baselines, crazy tilted perspectives, incongruous cropping and high or low vantage points" which, she demonstrates, are visual parallels for aerial views and tabletop photography. ${ }^{55}$ She writes of how for the painting of Standard Station, Amarillo, Texas (1963), Ruscha worked from tracings of the photograph (Fig 4), using a projector to enlarge photographs of the Los Angles apartments onto glass plates before reworking and exaggerating their perspective. ${ }^{56}$ Ruscha talks about seeing a landscape made of boxes, and these found boxes, occurring within the urban landscape become the subject through which Ruscha presents the effects of distance in the form of different physical points of view. ${ }^{57}$

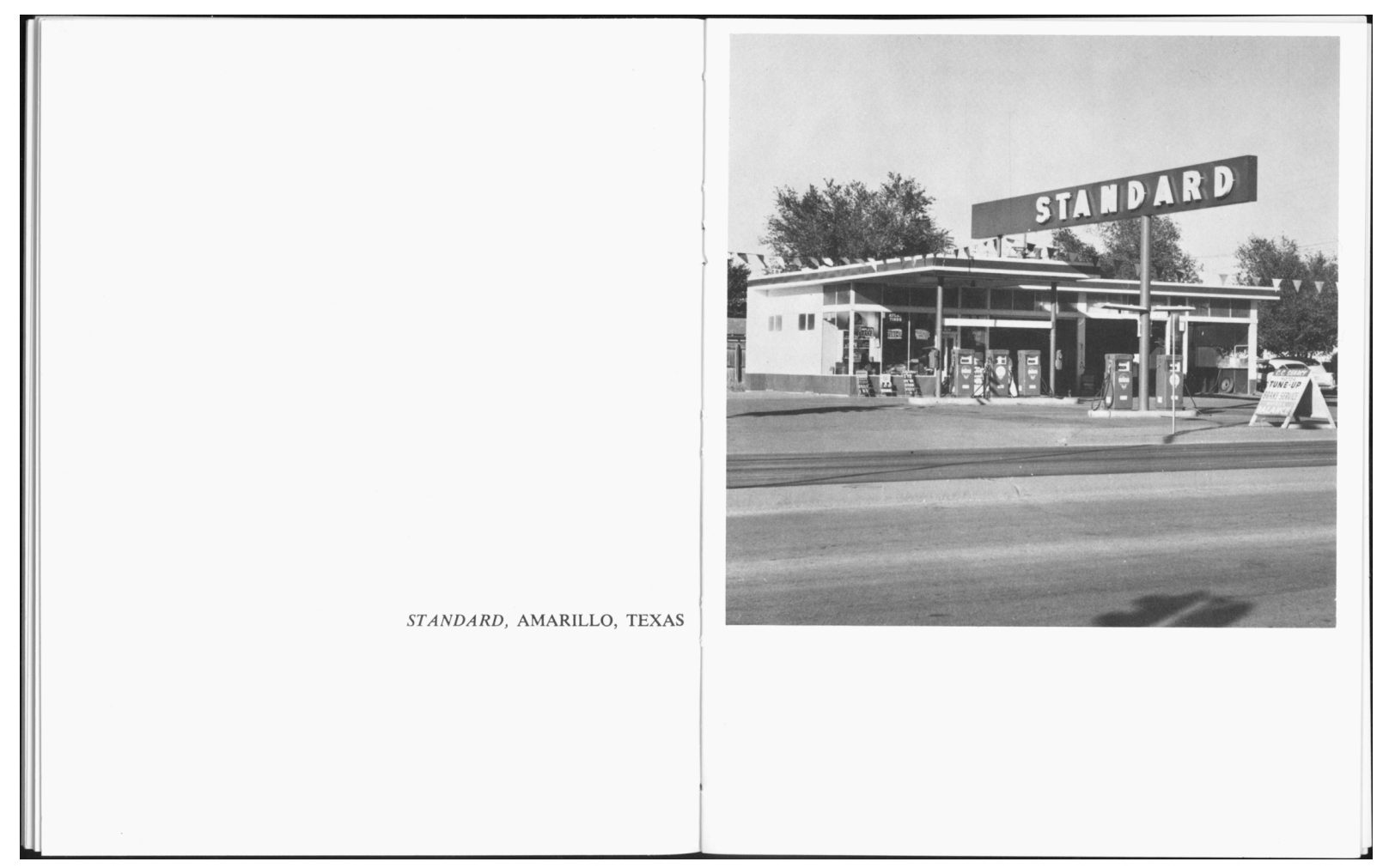


One of the most obvious results of this flattening is to emphasize the recessive diagonals of perspectival depth and the flat planes of the lots, pools and buildings that run along those lines. These oblique perspectives, particularly when they are shot over a distance and from the hip, as the gas stations appear to be, means that a lot of the photographic frame is filled by ground or by sky. Ruscha works with a copy of Millet's Ophelia in his studio, a painting which positions the viewer above Ophelia where, he says, "you're looking down on this woman in a sort of aerial oblique manner," giving us the woman in the plane of the water as a primary element of the composition. ${ }^{58}$ As Salvesen's visual comparison makes clear, one of the differences between Ruscha's photos in Real Estate Opportunities and actual real estate photography is that Ruscha's photos are taken on the oblique whilst the sales photos stay on the flat, and that realtor's photos crop out much of the ground or sky to throw focus onto the architecture. ${ }^{59}$ There is also a difference in detail; Ruscha's photos are printed much more finely.

What should, in a more utilitarian setting, be the ground of a "figure and ground" relationship is much more fully activated here so that the normal hierarchies of pictorial backgrounds and foregrounds do not hold. Real Estate Opportunities plays with this switch of emphasis: the first look at any of its photos is generally at the sweep of the view, then at the solid boxes of the buildings or of the cars, sometimes at the road between us and the lots, then a re-contextualization prompted by the real estate signage reminds us of the title, which moves our eye back to any expanses of grasses, asphalt or concrete in the foreground or negative space. This act of forcing us visually back into the secondary compositional elements makes the book quite difficult to look at for sustained amounts of time, and, as with the roadside vistas of the gasoline stations and apartment blocks, the distance of the camera from its subject is emphasized by the uncropped expanses of asphalt in the bottom third or half of many of these pictures. The parking lots, too, thematize visual distance, but this time vertically. It does not take much more than a drive up to Mulholland, or to the Hollywood Sign (which Ruscha also painted) to start seeing LA from above. "I guess I've always been intrigued by oblique perspectives, like aerial views. There's something about a tabletop ... taking a viewer up in the air, so you can look down from an angle," he says, and these pictures, like the paintings of Los Angeles County Museum on Fire (1968), make a subject out of those angles themselves. Even the photos of the parking lots which at first glance seem to be taken straight on, are in fact slightly oblique perspectives, a view that, like military 
photography, gives the viewer something between a flat and a solid mass, more useful for surveying buildings than the flat vertical shots which are used to produce maps. ${ }^{60}$

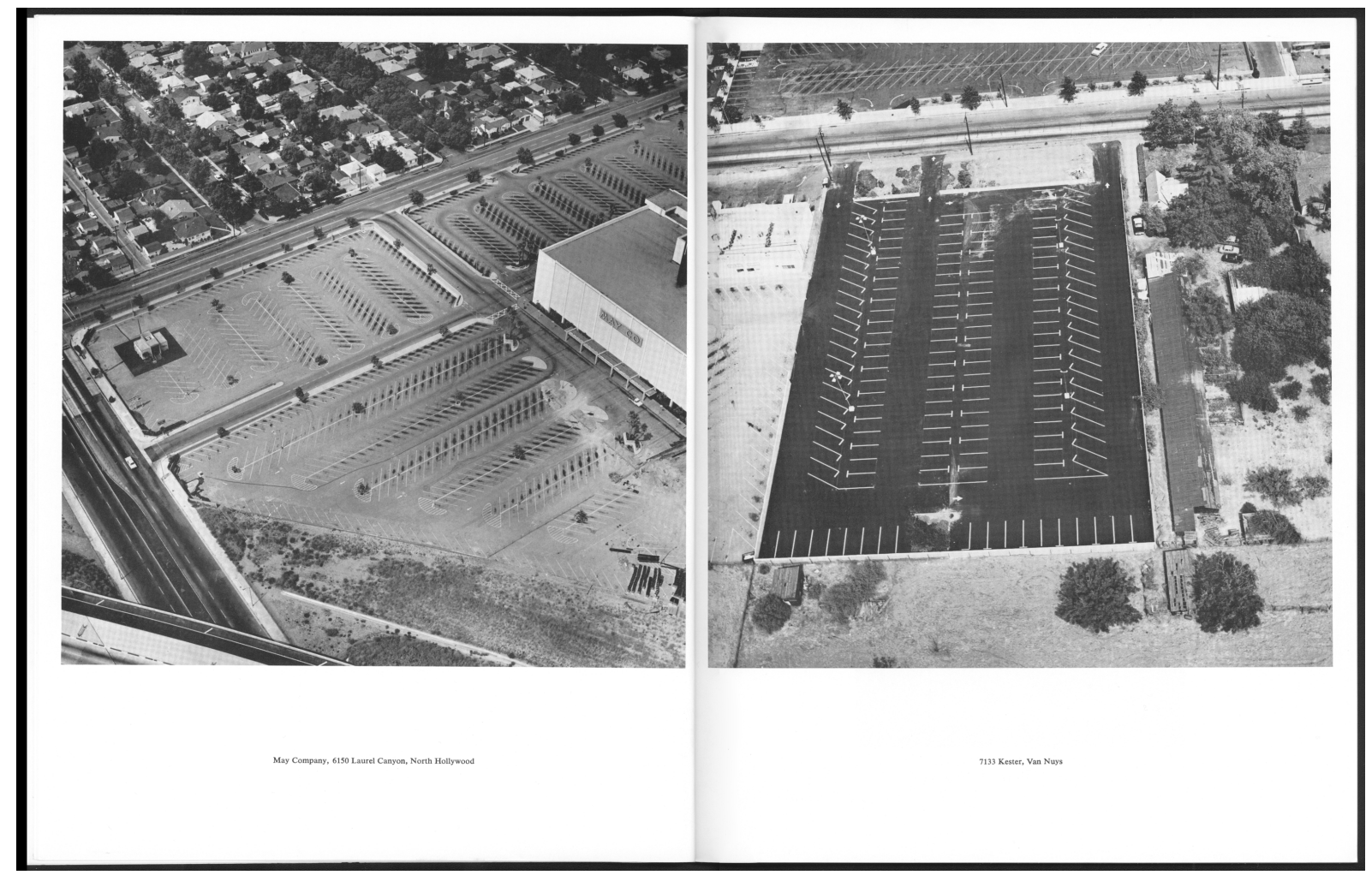

These large tracts of ground receding away from the camera, as well as the architectural obliques, come to dominate our vision of the photographs in part because the forced perspective of the diagonals exert a pull on the eye which is unmitigated by more obviously foregrounded elements. (This is why, in some ways, Nine Swimming Pools seems the least severe of the books - the diving boards lead the eye more naturally along the perspective lines, and the expanses of water give us the play of light, waves and reflection as subject.) In The Poetics of Perspective, James Elkins suggests that perspective lines can be felt as a form of entrapment; they "tug at the eye," "direct the gaze along orthogonals," producing a kind of "confining," "repetitive motion." 61 This dramatic "pull" of the eye is exploited by Ruscha throughout his work, in these photobooks, but also in the movie-based paintings too - for the Twentieth Century Fox logo in Large Trademark with Eight Spotlights (1962) and for his paintings of the Hollywood sign. Los Angeles as the land of the film industry is in Ruscha's work not just in its glossy texture, but also in these klieg light diagonals. Indeed, Ruscha speaks of combining the ideas of the Twentieth Century Fox logo with the movement of the movies as he was composing Standard Station.

The photograph was the model for other depictions, with its baseline perspective and its diagonal screaming overhead. It followed an idea I had about cinematic reality. ... It's not 
simply a story about a type of architecture that I might be interested in. It also echoes a memory I had of watching movies when I was young. It seemed like all movies would have a train in them. Invariably, they had the camera down on the tracks and shot this train so it appeared as though it was coming from nowhere, from a little point in the distance, to suddenly zooming in a filling your total range of vision. In a sense, that's what the Standard gas station is doing. It's super drama. ${ }^{62}$

The obliques and diagonals divide the picture plane to produce the impression of movement over distance, which, for Ruscha seems to mean that the lines of the cityscape become the "drama" of the work. The flattening of landscape onto the photographic surface is here performed with a celluloid surface, performing a similar feat of remediation to the drawings of the photobooks - in the Standard gas station canvases, paintings, produced from a tracing of a photograph, take their exaggerated lines from the flattened landscape of a filmed train.

This movement is most obviously present in Ruscha's dependence on the car for these photobooks. Ruscha's work gets identified with Los Angeles by his contemporary, British engineerturned-architectural historian Reyner Banham, because of its reliance on and consistent return to what Venturi, Izenour and Scott Brown call the "autoscape," but also because, perhaps, of its more general overall impression of movement over distance: "the language of design, architecture, and urbanism in Los Angeles is the language of movement," Banham argues. ${ }^{63}$ This extends to our viewing of Ruscha's work too. As Reynolds points out, by emphasising horizontality, surface and flatness Ruscha's work 
encourages us to scan the landscape of the picture, rather than to settle on a focal point. ${ }^{64}$ Photographs such as "Union, Needles, California" are works about the autoscape which also keep the eye moving.

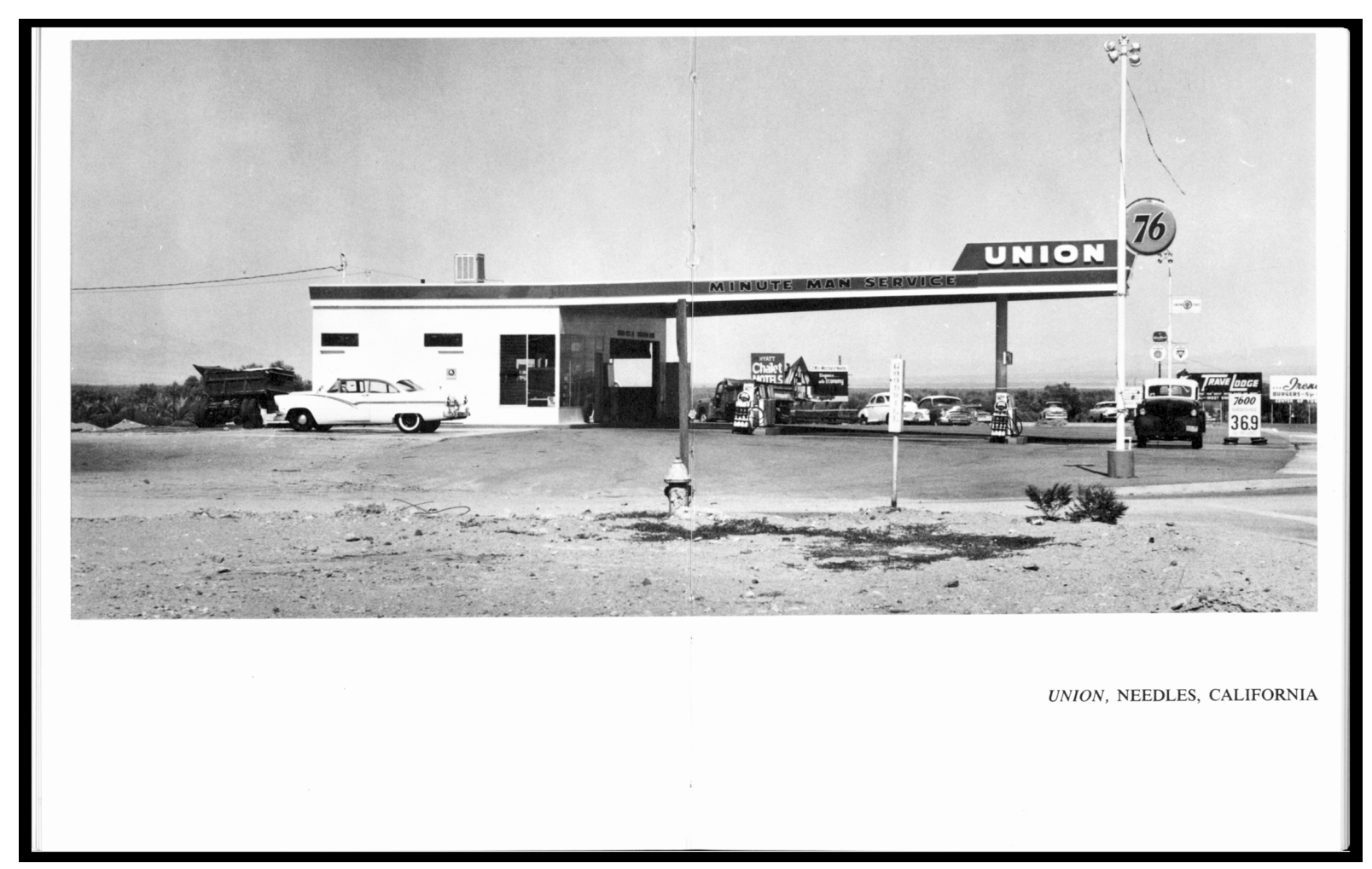

Ruscha was approached by architects interested in his photos of parking lots for their variety of markings and sense of the architecture of place, but he professed to be more interested in the oil stains, that is, the sense of trace left by movement over distance. ${ }^{65}$ From a systems point of view, however, both oil stains and fire lanes are traces. Architecture, Scott Brown, Izenour and Venturi argue, is "frozen process" and this too applies to the gaps and highways between architecture that Ruscha makes his own. In keeping with the sixties and seventies movement away from isolated objects and towards a set of philosophies of systems, ${ }^{66}$ Ruscha speaks of these photobooks as constituting a formal system: "once I established a format — the first one was agony — it was fluid because I had a format and I could almost fit these ideas. Each one could be plugged into the system I had. It's like a system of expression, if you want to look at it that way." 67 This aesthetic system for the photo books intersects with a phenomenological body-book-pictorial-space system, but also with the Los Angeles infrastructure that is their content. Royal Road Test is almost all road surface, and the photos in Twentysix Gasoline Stations (such as "Union," above) are as much a study of different conditions of asphalt as they are of the stations above them. In the Parking Lot photographs we get lots of lines, and bays, and fire lanes and tracks and 
roads: this is a ground that is dominated by the car, but also by the systems that direct those cars in flows. The flow is arrested in these empty lots, but it's still here in trace as arrows and skid marks. ${ }^{68}$ As Newbury argues, these photographs give us the spaces between the new industries of Southern California, showing us an infrastructure in the re-making. ${ }^{69}$

The textures of the photographs too, give us geography as much as they give us abstraction; set against the boxes and planes there are the textures of concrete, cracked scrub, grassland, wet tiling, rippled water, dusty highways, sun-bleached ground, and each one of those surfaces asserts their presence as a trace of human decisions or natural process. The backyards in 9 Swimming Pools shows assertive interventions into the environment; the startling blues and crisp shapes of the pools work in counterpoint with the debris of everyday life scattered on the poolsides. The concrete of the highways and parking lots are the traces of civil engineering designed to put humans in cars into processes, the vacant lots evidence more natural processes literally regaining their ground. Indeed, the new discipline of "Landscape Urbanism" continues this perspective to design horizontally, that is, across the horizon in landscapes rather than buildings, to attempt to mitigate this sense of cities as sprawling clusters of isolated objects with distances between.

If landscape is about vistas, or about depth, or about travels towards the horizon, then Ruscha's function differently. Where there is travel it is past something and over something. In Ruscha's parking lots the eye has no focal point to guide and rest it, and, in many respects, we are given a set of photos that, because of the arrows and lines painted on the ground, are indeed close to the notion of topography in their notation of maps, details, diagrams and functions. Having a perspective creates a landscape and a three-dimensional sense of the object in its environment, but oblique perspective brings it towards abstraction, and towards topography as the marks of those forces that structure and recreate that landscape. The inclusion of the viewer's body as part of the system of the work is manifest in these photobooks in the way that they are given to us as solid objects to be handled as well as read, as well as in their games with scale and movement. Through the emptied-out views, the photobooks insist on their geography and phenomenological geometry, and the body of the viewer is guided through these abstracted vistas as part of the underlying system that was South California's post-war infrastructure. Ruscha's thematization of affective distance may attempt to remove the romantic notion of the artist as going through and giving us exemplary experience, but it still positions us very clearly in terms of physical point of view. It is physical distance which produces the distinctively expanded foregrounds, the extreme high or low horizons, the pronounced diagonals, and the aerial perspectives that punctate these books. 
${ }^{1}$ Margit Rowell, "Ed Ruscha: Photographer," in Ed Ruscha, Photographer, Edward Ruscha and Margit Rowell (New York: Steidl and Whitney Museum of American Art, 2006), 11-42, 18.

${ }^{2}$ William Jenkins, "New Topographics: Photographs of a Man-Altered Landscape," in Photographic Theory: An Historical Anthology, ed., Andrew E. Hershberger (Chichester: Wiley Blackwell, 2014), 235-38, 236.

${ }^{3}$ For Jenkins, the connection between Ruscha's work and the sense of Robert Adams, Lewis Baltz, Bernd and Hilla Becher, Frank Gohlke, Nicholas Nixon and Stephen Shore as treating the landscape "topographically" was both evident and troubled. Ruscha was not included in the exhibition despite the obvious visual connection between, for example, the shared serial strategies of Ruscha and the Bechers, but comments on Ruscha's early sixties photobooks take up the first third of Jenkins' essay. See Greg Foster-Rice and John Rohrbach, eds., Reframing the New Topographics (Chicago: Center for American Places, 2010) for extended consideration of these relationships.

${ }^{4}$ Jenkins, "New Topographics," 236.

${ }^{5}$ See Britt Salvesen, "New Topographics," in Robert Adams, Lewis Baltz, Bernd and Hilla Becher, Joe Deal, Frank Gohlke, Nicholas Nixon, John Schott, Stephen Shore, Henry Wessel, Jr., New Topographics (Tucson: Centre for Creative Photography, University of Arizona; Rochester, New York: George Eastman House International Museum of Photography and Film; Gottingen: Steidl, 2013), 11-67, 27.

${ }^{6}$ Susanna Newbury "Thirtyfour Parking Lots in the Fragmented Metropolis," in Everything Loose Will Land: 1970s Art and Architecture in Los Angeles ed., Sylvia Lavin with Kimberli Meyer (New York: Distributed Art Publishers, 2013),50-5, 53.

${ }^{7}$ The negotiation of ambivalence is also part of the critical negotiation of the New Topographics exhibition, where, as Greg Foster-Rice, Toby Jurovics and Mark Rawlison point out, claims for the neutrality of the work of the American photographers are easily disputed. See Greg Foster-Rice, "Systems Everywhere," Mark Rawlinson, "Disconsolate and Inconsolable: Neutrality and new Topographics" and Toby Jurovics "Same As It Ever Was: Rereading New Topographics" in Reframing the New Topographics. Rawlinson gives a history for the critique of photographic neutrality in fn3.

${ }^{8}$ Eleanor Antin, "Reading Ruscha," Art in America, Volume 61, No 6 (November-December 1973), 64-71. Reprinted at http://www.artinamericamagazine.com/news-features/magazine/from-thearchives-reading-ruscha/.

${ }^{9}$ Edward Ruscha, oral history interview with Christophe Cherix, January 24, 2012, MoMA, 12; 11. https://www.moma.org/docs/learn/archives/transcript_ruscha.pdf.

${ }^{10}$ Margaret Iversen, "Auto-maticity: Ruscha and Performative Photography," Art History Volume 32, No 5 (December 2009), 836-51, 40.

${ }^{11}$ See Alexandra Schwartz, Ed Ruscha's Los Angeles (Cambridge, Mass: MIT Press, 2000), 203.

${ }^{12}$ Jenkins, "New Topographics," 237

${ }^{13}$ Salvesen, "New Topographics," 52.

${ }^{14}$ Sol Lewitt, Serial Project \#1, Aspen, 5+6 (1968).

${ }^{15}$ See Edward Ruscha, Leave Any Information at the Signal: Writing, Interviews, Bits, Pages, ed., Alexandra Schwartz (Cambridge. Mass: MIT Press, 2012), 263.

${ }^{16}$ See Ruscha in Schwartz, Leave Any Information at the Signal, 373

${ }^{17}$ See Schwarz, Ed Ruscha's Los Angeles, chapter 4.

18 "TateShots: Ed Ruscha's Photography Books," Tate.org. $6^{\text {th }}$ September 2013. Accessed May $1^{\text {st }}$ 2017. www.tate.org.uk/context-comment/video/tateshots-ed-ruschas-photographybooks

19 "TateShots," Tate.org.

${ }^{20}$ See the parodies and homages collected in Various Small Books, ed., Jeff Brouws, Wendy Burton and Hermann Zschiegner (Cambridge, Mass.: MIT Press, 2013).

${ }^{21}$ Salvesen, "New Topographics," 16.

${ }^{22}$ As Michael Petry explains in The Art of Not Making: The New Artist/Artisan Relationship, this is the paradox in Duchamp's idea of the artist, too: if there is little difference between the art object and 
the maker's object the artist's name becomes even more important in shoring up its market value (London: Thames and Hudson, 2011),9.

${ }^{23}$ Ruscha in Schwartz, Leave Any Information at the Signal, 23.

${ }^{24}$ Aspen, 8 (1970-71).

${ }^{25}$ Gagnon, Charles, "Handling Conceptual Art," Centre for Sensory Studies, Occasional Papers.

Concordia University. http://centreforsensorystudies.org/wp-content/uploads/2011/09/OP-Gagnon-

Handling-Conceptial-Art.pdf Accessed 28th Jan 2017.

${ }^{26}$ Schwartz, Ed Ruscha's Los Angeles, 203.

${ }^{27}$ Ruscha in Schwartz, Leave Any Information at the Signal, 47.

${ }^{28}$ Antin, "Reading Ruscha".

${ }^{29}$ Robert Adams in Carol di Grappa, ed., Landscape: Theory (New York: Lustrum, 1980), 6; see also Rawlinson "Disconsolate and Inconsolable."

${ }^{30}$ See Helen Molesworth, Part Object Part Sculpture (Columbus, Ohio: Wexner Center for the Arts, The Ohio State University; University Park, Pa.: Pennsylvania State University Press, 2005),183-185.

${ }^{31}$ Ruscha in Schwartz, Leave Any Information at the Signal, 330, 215.

${ }^{32}$ Ibid., 330, 230 italics in original.

${ }^{33}$ There may also be a sly reference to Duchamp in the Parking Lots in the way that the shape of the Dodgers stadium from above echoes Alfred Stieglitz' photograph of Duchamp's Fountain.

${ }^{34}$ Ruscha in Schwartz, Leave Any Information at the Signal, 297.

${ }^{35}$ Sol Lewitt, "Paragraphs on Conceptual Art" in Conceptual Art: A Critical Anthology, ed., Alexander Alberro and Blake Stimson (Cambridge, Mass: MIT Press, 1999), 12-16, 12.

${ }^{36}$ Sianne Ngai, "Merely Interesting," Critical Inquiry Volume 34, No 4 (2008), 777-817, 788.

${ }^{37}$ Ngai, "Merely Interesting," 795. In other readings, this disarming feeling has often been evoked through citation of Ruscha's comment that "this book had an inexplicable thing I was looking for, and that was a kind of a 'Huh?'.” Ruscha in Schwartz, Leave Any Information at the Signal, 65.

${ }^{38}$ Salvesen, "New Topographics," 28.

${ }^{39}$ Ibid., 28.

${ }^{40}$ Ian Walker reads them as parodying ideas of photography as archive: "This seeming off-handedness disturbed the very logic of the class or category as a careful and rationally considered structure of thinking," he writes. "A Kind of a 'Huh?"': The Siting of Twentysix Gasoline Stations (1962)' in Patrizia Di Bello, Colette Wilson and Shamoon Zamir. eds., The Photobook: From Talbot to Ruscha and Beyond (London: I.B. Tauris, 2012), 178-203, 195.

${ }^{41}$ This subsuming of the personal and contingent in favour of geometric precision is part of what Dan Graham, in Homes for America (1966), finds in Ruscha's work and in the shapes of tract houses. For Graham and Ruscha Minimalist serialism picks up on a uniformity that is already extant in the topographical ubiquity of the flattened plane and the box, its repetition with variation an essential part of its physical character.

${ }^{42}$ Ruscha in Schwartz, Leave Any Information at the Signal, 340.

${ }^{43}$ And it is this uneasy relationship with humanist ideas of personal vision that might see Ruscha as marking a break in the pictorialist lineage that descends through older American photographers such as Minor White or Aron Siskind (or Paul Strand and Edward Weston) who were also concerned with abstraction, and that - as Jenkins urged in his selections for "New Topographics" - might indeed align him more clearly with the anti-subjective concerns of Baltz et al.

${ }^{44}$ See Edward Ruscha, Oral history interview with Paul Karlstrom, October 29th, 1980 - October 2, 1981. Archives of American Art: Smithsonian Institution.

http://www.aaa.si.edu/collections/interviews/oral-history-interview-edward-ruscha-12887 Accessed $1^{\text {st }}$ May 2017.

${ }^{45}$ Ruscha in Schwartz, Leave Any Information at the Signal, 53, 62.

${ }^{46}$ Ken D. Allan, "Ed Ruscha, Pop Art, and Spectatorship in 1960s Los Angeles," The Art Bulletin Volume 92 No 3 (2010), 231-49, 231.

${ }^{47}$ Allan, "Ed Ruscha, Pop Art, and Spectatorship in 1960s Los Angeles," 236; Ruscha in Schwartz, Leave Any Information at the Signal, 303. 
${ }^{48}$ Allan, "Ed Ruscha, Pop Art, and Spectatorship in 1960s Los Angeles," 242.

${ }^{49}$ See Aron Vinegar, "Ed Ruscha, Heidegger, and Deadpan Photography," Art History Volume 32, No 5 (December 2009), 852-73.

${ }^{50}$ See Standing Gasoline Station Books, 1963, Twentysix Gasoline Stations (table setting), 1963, Twentysix Gasoline Stations, 1964 (Graphite on paper - tryptic), Three Hanging Books, 1972 (gunpowder and pastel on paper).

${ }_{51}^{5}$ Allan, "Ed Ruscha, Pop Art, and Spectatorship in 1960s Los Angeles," 244.

${ }^{52}$ Here too, there may be a Duchampian intertext in the form of Man Ray's photographs of the Large Glass covered in dust (Dust Breeding, 1920). For Ruscha on Man Ray see Smithsonian oral history.

${ }^{53}$ Every Building on the Sunset Strip was taken with "a perspective control lens 'set at infinity'. The infinity setting is used in commercial photography primarily for capturing distant landscapes. But the relatively close proximity to the structures of Ruscha's images resulted in a "snapshot" aesthetic in which buildings and streets are characterized by a lack of depth. The flatness of the photographs makes the spaces appear artificial, as if they were facades built for a movie set." Matt Reynolds, "Landscape in Motion: Nostalgia and Urban Redevelopment in Ed Ruscha's Then and Now: Hollywood Boulevard, 1973 to 2004", Journal of Urban History Volume 41, No 6 (2015), 1052-72, 56.

${ }^{54}$ Rowell, "Ed Ruscha: Photographer,"17. Rowell argues that: "photography helped him see and transpose things flat. It inspired the precision of his crisp edges and engendered his formal devices of horizontal or diagonal baselines, crazy tilted perspectives, incongruous siting or cropping, and high or low vantage points related to tabletop photography and aerial views," 37-38.

${ }^{55}$ Ibid.

${ }^{56}$ Ibid., 24.

${ }^{57}$ Interview at Moderna Museet, Stockholm. 29 May 2010. https://youtu.be/J-g17EL7ptk. Accessed 1st May 2017.

${ }^{58}$ Ruscha in Schwartz, Leave Any Information at the Signal, 375.

${ }^{59}$ Salvesen, "New Topographics," 27.

${ }^{60}$ Ruscha states: "Perhaps the obliques are from nonart utilitarian photographs, aerial views, military photographs, scientific photographs. All these utilitarian photographs influenced the act of picturemaking." Rowell, "Ed Ruscha: Photographer," 27.

${ }^{61}$ James Elkins, The Poetics of Perspective (Ithaca: Cornell University Press, 1994), 176.

${ }^{62}$ Rowell, "Ed Ruscha: Photographer," 18. Also: "You know those movies where a train starts out in the lower-right corner and gradually fills the screen?' he asked. 'The gas station is on a diagonal like that, from lower right to upper left. It also had something to do with teachings I picked up in art school, about dividing the picture plane'." Calvin Tompkins, "Ed Ruscha's LA: An Artist in the Right Place," New Yorker.com, July 1st 2013. http://www.newyorker.com/magazine/2013/07/01/ed-ruschas1-a Accessed 1st May 2017. See also MoMA oral history, 46.

${ }^{63}$ Reyner Banham, Los Angeles: The Architecture of Four Ecologies (Berkeley: University of California Press, 2009), 5.

${ }^{64}$ Reynolds, "Landscape in Motion: Nostalgia and Urban Redevelopment in Ed Ruscha's Then and Now: Hollywood Boulevard, 1973 to 2004," 1065.

${ }^{65}$ In Thirtyfour Parking Lots Ruscha observes that "the largest and most saturated spots indicate which spaces are the most favoured and parked upon," Leave Any Information at the Signal, 43.

${ }^{66}$ For the confluence between the New Topographics work and systems art see Greg Foster-Rice, "Systems Everywhere" in Reframing the New Topographics.

${ }^{67}$ Ruscha in Schwartz, Leave Any Information at the Signal, 212.

${ }^{68}$ Perhaps here we can see a kind of antagonistic relationship with time similar to the one Pamela Lee writes of in Chronophobia: On Time in the Art of the 1960s (Cambridge, Mass.: MIT Press, 2006).

${ }^{69}$ Newbury "Thirtyfour Parking Lots in the Fragmented Metropolis," 55. 